\title{
Article
}

\section{Impact of the Confinement Plate on the Velocity of Synthetic Jet}

\author{
Emil Smyk ${ }^{1, *(\mathbb{D})}$ and Robert Smusz ${ }^{2}$ \\ 1 Faculty of Mechanical Engineering, Bydgoszcz University of Science and Technology, \\ 85-796 Bydgoszcz, Poland \\ 2 Department of Mechanical Engineering, Rzeszow University of Technology, 35-959 Rzeszow, Poland; \\ robsmusz@prz.edu.pl \\ * Correspondence: emil.smyk@pbs.edu.pl
}

\section{check for}

updates

Citation: Smyk, E.; Smusz, R. Impact of the Confinement Plate on the Velocity of Synthetic Jet. Actuators 2021, 10, 208. https://doi.org/ $10.3390 /$ act 10090208

Academic Editor: Luigi de Luca

Received: 26 July 2021

Accepted: 25 August 2021

Published: 27 August 2021

Publisher's Note: MDPI stays neutral with regard to jurisdictional claims in published maps and institutional affiliations.

Copyright: (c) 2021 by the authors. Licensee MDPI, Basel, Switzerland. This article is an open access article distributed under the terms and conditions of the Creative Commons Attribution (CC BY) license (https:// creativecommons.org/licenses/by/ $4.0 /)$.

\begin{abstract}
In the paper, the impact of the limitation of the environment around the office of synthetic jet actuators were tested. One short and three length orifices were tested and compared with and without confinement plate. In total, seven different synthetic jet actuators were investigated. The constant temperature anemometer was used for the velocity measurements. The synthetic jet was tested for the Reynolds number in the range of $2300<R e<19,500$, and the Stokes number in the range of $46<S<62$. The confinement plate decreased the velocity of synthetic jet depending on the actuator supply power even around $5 \%$. However, the differences in axial velocity profile are slight and the impact of the confinement plate was visible only in the distance $x / d<4$.
\end{abstract}

Keywords: synthetic jet; confinement plate; ZNMF; efficiency

\section{Introduction}

The synthetic jet (SJ) has potential application in the areas of mixing enhancement [1-4], heat transfer $[5,6]$, mass transfer $[7,8]$, and widely understood active flow control $[9,10]$. The physic parameters, the topology, and the performance of SJ are mainly dependent on the geometrical and the supply parameters of the synthetic jet actuator (SJA). Due to many applications of SJ, many ways to increase the efficiency of SJA, the velocity of SJ, or other parameters depending on the area of application and requirement.

Singh et al. [11] investigated the acoustic SJA with one circular, rectangular, or square orifice for different orifice thicknesses. The SJ was used as an impingement jet and the average and local Nusselt number on the heated plate was measured. The measures heat transfer coefficient in the case of the SJ impingement jet was about 16 higher than in the case of natural convection. The highest value of the average Nusselt number was achieved for the rectangular orifice (around 25\% and 33\% higher than in the case of the square and circular orifice). The same authors investigated in more detail this issue in [12] and showed that the use of more than one orifice can increase the average Nusselt number by around $60 \%$. This was also confirmed numerically. Jacob et al. [13] investigated the impinging SJ generated by actuators with one, two, and four circular orifices. The more orifices the higher heat transfer but this effect was strongly dependent on the orifice-plate distance.

Miro et al. [14] investigated the flow topology of rectangular (slot) and circular impinging SJ. The turbulent mixing was higher in the case of the rectangular orifice, but the circular SJ leads to a higher heat transfer peak. It is caused by the different size and velocity distribution (topology) of the slot and circular SJ. Miro et al. [14] used the numerical simulation but the topology difference depending on the orifice shape was more widely described and shown in [15,16]. Zong and Katsonis [15] used the Schlieren and particle image velocimetry (PIV) methods and Gaputa et al. [16] used laser-induced fluorescence (LIF) and PIV methods. In papers $[15,16]$ was showed that the formation and evolution of SJ are strongly dependent on the actuator orifice shape.

Bhapkar et al. [17] showed that the outer shape of the actuator cavity has an impact on the SJ impingement cooling. The effect of the cavity shape was high for a small orifice-plate 
distance. For the flat cavity wall and small orifice-plate distance between the orifice and heated plate was created in the closed space. The mixing of the air from this space and environment is strongly limited and the cooling efficiency decreased. The use of the round cavity allows for easier removal of hot air from the space between the actuator body and the plate and increased the heat transfer.

The heat transfer enhancement can be realized not only by SJA modification. One of the most effective methods is the use of heat sinks [18,19]. Mangate and Chaudhari [19] provide that the use of the heat sink can increase the heat transfer coefficient even around seven times. They used multiple- orifices impinging SJ. Gil $[20,21]$ closed the heat sink in the actuator chamber. This solution has smaller sizes compared to the classic impinging SJ (the cooled surface is the part of the actuator).

The efficiency of the SJ can be also increased by increasing the parameters of the synthetic jet. Ferro et al. [22] investigated experimentally the impact of the cavity shape on the SJ performance. They tested three shapes of the cavity: cylindrical, conical, and contraction. The cylindrical cavity of SJA minimalized momentum flux while the contraction cavity reduces the power consumption and increased actuator electrical efficiency.

Smyk et al. [23] investigated the impact of the confinement plate on the SJ. While, Mangate and Chaudhari [19] investigate the impact of confinement plate in the cooling application, in paper [23] the focus was on whether the confinement plate influences the SJ and actuators parameters. The presented results indicated that the limitation of the environment around the office has a negative impact on the SJ parameters. However, the dependences were not unambiguous.

The velocity of SJ and the efficiency of the actuator can be also increased by the appropriate design and selection of the resonant frequency of the actuator [24-26] or the design of an optimal orifice diameter [27]. However, in this paper, we want to focus on the idea presented in [23] and check whether the coefficient plate decreased the velocity of SJ and impact other parameters.

\section{Materials and Methods}

The SJA was made from PMMA and the loudspeaker STX W.18.200.8.FGX $(8 \Omega)$ was used for the SJ generation. The diameter of the actuator cavity was $150 \mathrm{~mm}$ and the cavity height was $20 \mathrm{~mm}$. Six different orifices were investigated: one short (case 0 ) and three long (case 1, 2, and 3). A short orifice is understood to mean a nozzle with a ratio $t / d<1$, and a long the orifice with a ratio $t / d \geq 1$, where $t$ is the orifice height, and $d$ is the orifice diameter. The orifice was extended by attaching to the SJA body a special extension made with the use of the 3D printing method. The outer area of the orifice was $24 \mathrm{~mm}$.

During parts of tests with the actuators with the long orifice, the confinement plate on the end of the orifice was used. The plate reduces the space around the orifice outlet. In the case of actuators without the confinement plate, this role was played by the frontal surface of orifice extension. The case of the SJA with the confinement plate was marked with " $\mathrm{A}$ ", and without the plate with " $\mathrm{B}$ ". The area of the confinement plate was $A=25,132.74 \mathrm{~mm}^{2}$. It was also the area of the frontal surface of the actuator body. The area of the orifice front surface was $138.23 \mathrm{~mm}^{2}$.

The models of the actuators were presented in Figure 1a. The most important parameters of SJA were presented in Table 1.

The Rigol DG4162 waveform generator was used to suppling the SJA with a harmonic electric current. The LM3886 Texas Instruments amplifier was additionally used to strengthen the signal. The electrical power was measured with two Keithley 2701 multimeter (6.5 digit, 22-Bit) with 7706 all in one I/O module (20 analog input). The first multimeter measured the voltage drop on the loudspeaker and the second measured the current indirectly by measuring the voltage drop on the reference resistor $(1 \Omega, 0.01 \%)$. Data was recorded using a multifunction board National Instruments USB-6211.

The velocity was measured with a two-wire constant temperature anemometer (CTA) probe connected to the ATU 08 bridge. The first wire of the CTA probe was used for the 
velocity measurements and was calibrated in a range of $0.3-49 \mathrm{~m} / \mathrm{s}$. The second wire was used for the temperature measurements and the temperature compensation of the velocity. The CTA probe was positioned by the 3D manipulator with $\pm 0.02 \mathrm{~mm}$ positioning accuracy. The sampling rate was 2000 samples per one SJA operation period and the velocity was calculated based on 100 cycles.

Table 1. Matrix of parameters.

\begin{tabular}{|c|c|c|c|c|}
\hline & $\begin{array}{c}\text { Orifice Diameter } \\
d, \mathrm{~mm}\end{array}$ & $\begin{array}{c}\text { Orifice Height } \\
t, \mathrm{~mm}\end{array}$ & $t / d$ & $\begin{array}{c}\text { Confinement Area } \\
\qquad A, \mathrm{~mm}^{2}\end{array}$ \\
\hline Case 0 & 20 & 5 & 0.25 & $25,132.74$ \\
\hline Case 1A & 20 & 20 & 1 & $25,132.74$ \\
\hline Case $2 \mathrm{~A}$ & 20 & 40 & 2 & $25,132.74$ \\
\hline Case 3A & 20 & 60 & 3 & $25,132.74$ \\
\hline Case 1B & 20 & 20 & 1 & 138.23 \\
\hline Case 2B & 20 & 40 & 2 & 138.23 \\
\hline Case 3B & 20 & 60 & 3 & 138.23 \\
\hline
\end{tabular}

The barometric pressure was measured with a Honeywell HPB200W2DA-B barometer with accuracy $\pm 40 \mathrm{~Pa}$. The uncertainty of the other measured values was presented in Table 2, and the test stands in Figure 1b.
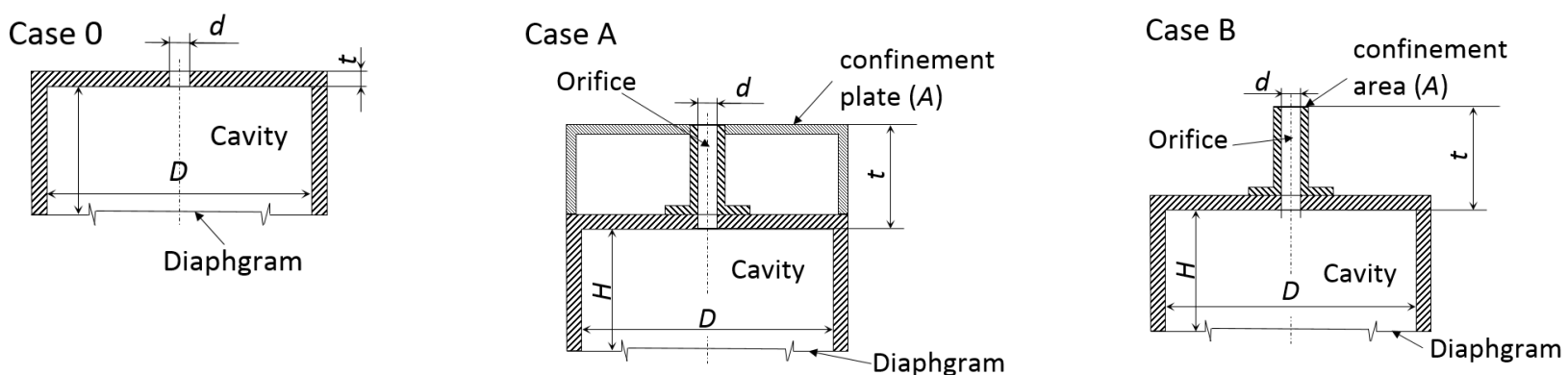

(a)

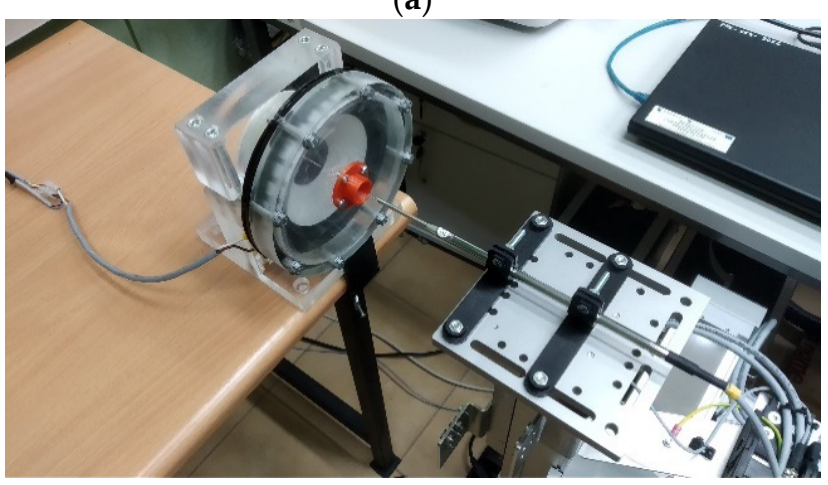

(b)

Figure 1. The model of SJA (a), and the test stand with the actuator $1 \mathrm{~B}(\mathbf{b})$.

Table 2. Uncertainty of measurements.

\begin{tabular}{ccc}
\hline Name & $\begin{array}{c}\text { Relative } \\
\text { Uncertainty }\end{array}$ & $\begin{array}{c}\text { Absolute } \\
\text { Uncertainty }\end{array}$ \\
\hline Area, $A$ & $\pm 0.15 \%$ & \\
Power, $P$ & $\pm 2 \%$ & \\
Velocity, $u$ & $\pm 2 \%(2.6-49 \mathrm{~m} / \mathrm{s})$ & $\pm 0.1 \mathrm{~m} / \mathrm{s}(<2.6 \mathrm{~m} / \mathrm{s})$ \\
\hline
\end{tabular}




\section{Data Reduction}

The present paper is an extension of research presented in [23] and is focused on the velocity measurements and the Reynolds number and the stroke length will be used for quantification of SJ. These parameters can for circular orifice be defined on the basis of the local centerline momentum velocity [28,29]:

$$
\begin{gathered}
R e=\frac{U_{c} d}{v} \\
L_{0} / d=\frac{U_{c} T}{d}
\end{gathered}
$$

where $d$ is the orifice diameter $[\mathrm{m}], v$ is the kinematic viscosity of fluid $\left[\mathrm{m}^{2} / \mathrm{s}\right], T$ is period of actuator operation $(T=1 / f)[s], f$ is a loudspeaker excitation frequency [s], and $U_{c}$ is the centerline momentum velocity defined as:

$$
U_{c}=\sqrt{\frac{1}{T} \int_{0}^{T}\left(u^{2}\right) d \tau}
$$

where $u(\tau, x, r=0)$ is instantons velocity at a certain axial distance $[\mathrm{m} / \mathrm{s}]$ and $\tau$ is a specific moment of time [s]. The ratio between the velocity averaged over the entire cross-sectional area and the velocity in the centerline is strictly defined [29,30].

The velocity parameters as maximal, minimal velocity and peak-to-peak velocity were determined:

$$
\begin{gathered}
U_{\max }=\max (u) \\
U_{\min }=\min (u) \\
U_{p-p}=U_{\max }+\left|U_{\min }\right|
\end{gathered}
$$

Additionally, the Stokes number was determined for the prepared measurements. The Stokes number can be calculated from:

$$
S=d \sqrt{\frac{2 \pi f}{v}}
$$

\section{Results and Discussion}

\subsection{Resonant Frequency}

The first step during the SJ investigation is always to find the resonant frequency of SJA. For this purpose, the velocity for different operating frequencies of the loudspeaker was measured at real power $p=3 \mathrm{~W}$ and axial distance $x=0$. The frequency was tested in the range of $8-50 \mathrm{~Hz}$ with the step of $1 \mathrm{~Hz}, 50-100 \mathrm{~Hz}$ with the step of $2 \mathrm{~Hz}$. The results were presented in Figure 2.

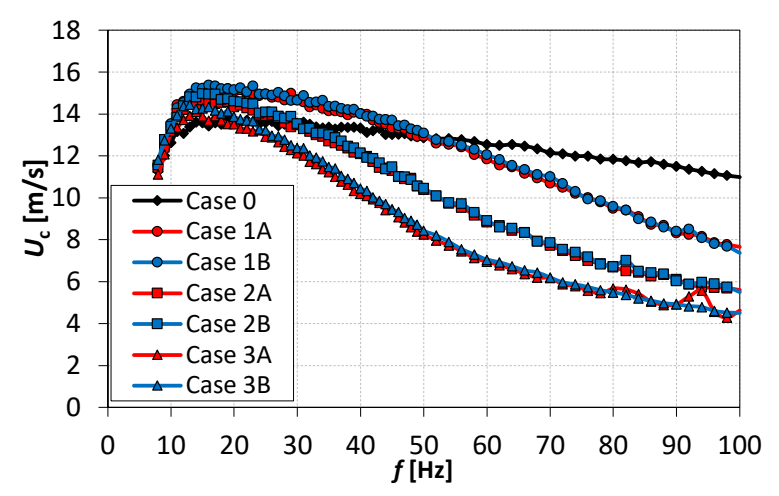

Figure 2. The centerline momentum velocity as a function of frequency at $p=3 \mathrm{~W}, x=0$. 
Based on the velocity measurements the resonant frequencies were designated. They were similar to in case of [23], where the same actuators were tested but with other measurements method (thrust method [31,32]). The resonant frequencies and the momentum velocities for these frequencies were presented in Table 3.

Table 3. Resonant frequencies and velocity.

\begin{tabular}{cccccc}
\hline & $\begin{array}{c}\text { Frequency, } \\
f_{r}, \mathbf{H z}\end{array}$ & $\begin{array}{c}\text { Velocity } \\
\boldsymbol{U}_{\mathbf{c}}\left(f_{r}\right)[\mathbf{m} / \mathbf{s}]\end{array}$ & $\begin{array}{c}\text { Frequency from [23] } \\
\boldsymbol{f}_{r, \mathbf{1}}, \mathbf{H z}\end{array}$ & $\begin{array}{c}\text { Velocity } \\
\boldsymbol{U}_{\mathbf{c}}\left(\boldsymbol{f}_{\boldsymbol{r}, \mathbf{1}}\right)[\mathbf{m} / \mathbf{s}]\end{array}$ & $\begin{array}{c}\text { Velocity Relative } \\
\text { Difference, } \%\end{array}$ \\
\hline Case 0 & 19 & 13.84 & 28 & 13.51 & 2.4 \\
Case 1A & 19 & 15.21 & 22 & 14.94 & 1.7 \\
Case 2A & 15 & 14.67 & 16 & 14.57 & 0.7 \\
Case 3A & 14 & 14.09 & 16 & 14.67 & 3.0 \\
Case 1B & 16 & 15.37 & 22 & 14.95 & 3.4 \\
Case 2B & 16 & 14.95 & 16 & 14.33 & 0 \\
Case 3B & 13 & 14.44 & 16 & & 0.8 \\
\hline
\end{tabular}

The velocity was weakly dependent on the coefficient wall-velocity was on average $1.2 \%$ larger in cases $\mathrm{A}$-but was inversely proportional to the orifice height, and it is in line with other studies $[33,34]$. The lowest velocity was obtained in case 0 and it is surprising and incompatible with measurements presented in [23], wherein in case 0 the highest time-mean reaction force was obtained.

The peak-to-peak velocity was presented in Figure 3. The peak-to-peak velocity was regardless of the confinement plate and in all cases except case 0 was strongly dependent on the frequency. In case 0 , it was equal to $33.8 \pm 3.8 \mathrm{~m} / \mathrm{s}$ and it achieved the highest value close to the resonant frequency. This apparent immutability and the previously mentioned difference are due to a short orifice, in our opinion.

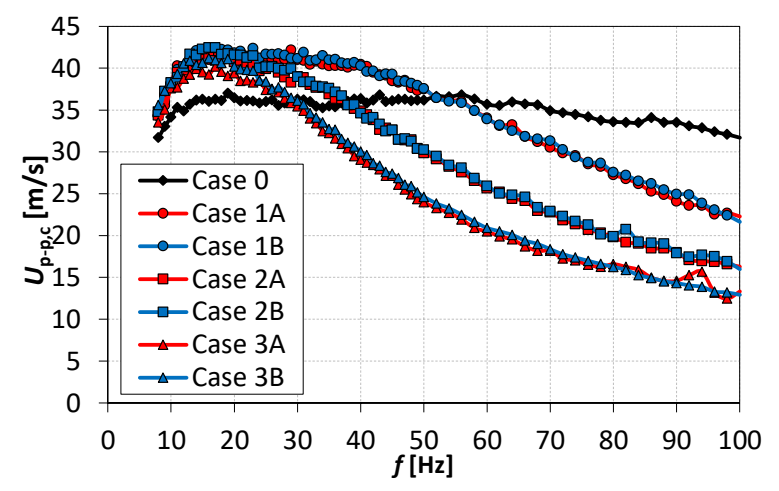

Figure 3. The peak-to-peak, centerline velocity as a function of frequency at $p=3 \mathrm{~W}, x=0$.

In a long orifice, the jet flowing out of the chamber has enough distance and time to stabilize its parameters, e.g., develop a velocity profile. In the case of a short orifice, the jet does not have enough distance and time to fully develop, and its parameters will be developed significantly after expulsion from the orifice. It explains why the peak-to-peak velocity in case 0 is almost constant irrespective of the operating frequency-be further confirmed by measuring the velocity of the axial profile. It explains also why the velocity in case 0 at the resonant frequency is the lowest, while the reaction force from [23] indicates that it should be the highest. The method of SJ parameters determination with reaction force measurements is independent of the orifice shape or number and determines the parameters for the entire SJ. The velocity measurement is carried out in a point or plane and therefore does not reflect the global state of SJ.

The resonant frequencies designed with the velocity measurements method and thrust method from [23] was similar and only in case 0 the resonant frequency differs significantly but the velocity relative difference between the velocity for resonant frequency designed 
for the actuators in this paper and the velocity for resonant frequency designed in [23] is below $3.5 \%$. For this reason, and to be able to compare these two papers with each other, subsequent measurements were conducted for frequency $f_{r, 1}$ from [23].

Differences in the designated resonant frequencies were not caused by the different methods used in compared investigations-in [23] the resonant frequencies were indicated on the base of the power factor. However, to verify this, a measurement of the power factor was made Figure 4 . The power factor for the resonant frequency tends to value one [35] and the resonant frequencies designed on the base of the power factor overlap with frequencies values designed based on velocity. It must therefore be assumed that the differences in the results originate regardless of the method and can be a result of wear and tear of equipment or measurement conditions.

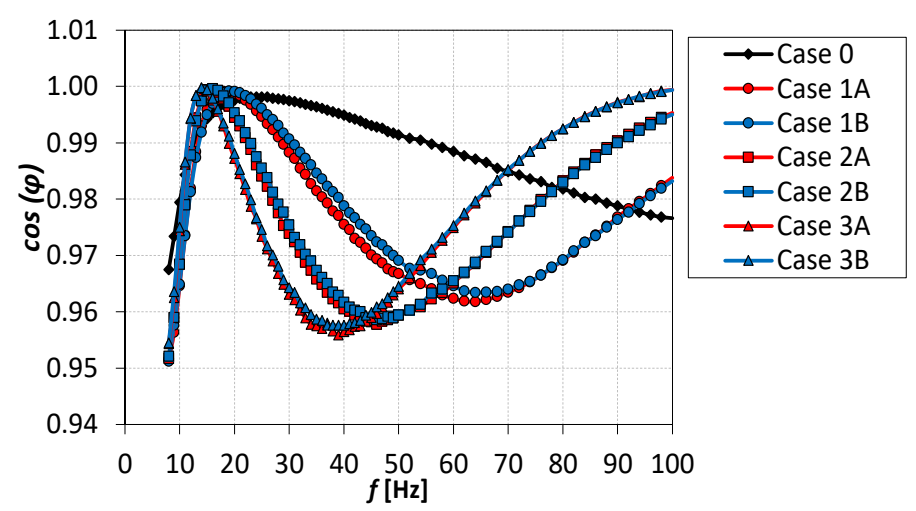

Figure 4. The power factor as a function of frequency at $p=3 \mathrm{~W}$.

\subsection{Impact of the Confinement Plate}

The centerline momentum velocity Figure 5 a was higher in B cases than in cases A, on average by $1.2 \%$ in case 1 , by $1.0 \%$ in case 2 , and by $2.9 \%$ in case 3 . This difference was smaller than the velocity uncertainty Table 2 which was $2 \%$ for the velocity above $2.6 \mathrm{~m} / \mathrm{s}$. For this reason, in Figure $5 \mathrm{~b}$ the difference between the velocity in case B and case A is presented and the level of the velocity uncertainty was marked with a red line.

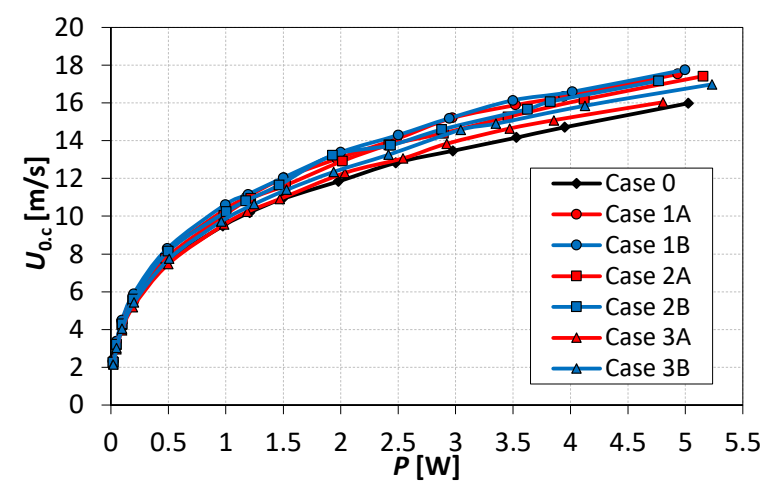

(a)

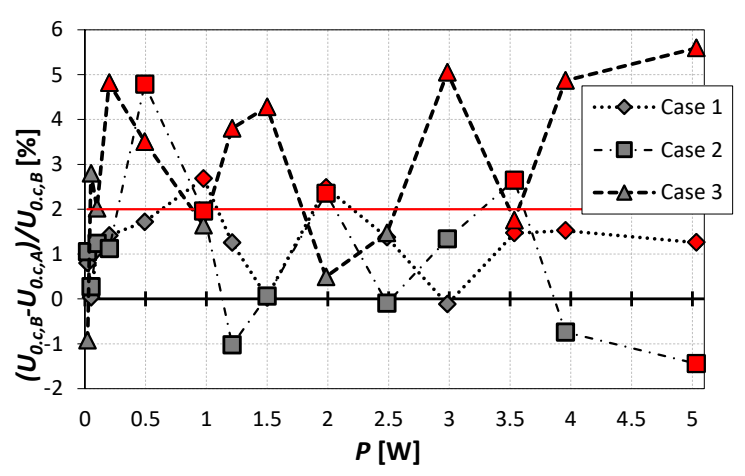

(b)

Figure 5. The centerline momentum velocity (a), and the percentage difference between the velocity in cases B and A (b) as a function of real power, at the characteristic frequency and $x=0$.

The differences between casa A and B for cases 1 and 2 are slight and greater than the measurement uncertainty only at a few real power values. However, in case 3 the differences are significant. The velocity in case $3 \mathrm{~B}$ was higher than the velocity in case $3 \mathrm{~A}$ for 9 from 14 investigated real power value and only at $p=0.02 \mathrm{~W}$ the velocity was higher in case 3A. Of course, the velocity uncertainty applies to both measurements and the line of $2 \%$ difference which was taken as the cut-off line is of a contractual nature. The measurement uncertainty for the velocity above $2.6 \mathrm{~m} / \mathrm{s}$ is equal to $0.1 \mathrm{~m} / \mathrm{s}$ (see Table 2). 
Therefore to be sure, that the velocity in case B is higher than in case A is higher the difference between them should be higher than $0.2 \mathrm{~m} / \mathrm{s}$ - assuming that the error of each measurement is the most unfavorable. This condition is met at 5 different real power in cases 1 and 2, and 8 different real power in cases 3 (these points were marked red in Figure $5 \mathrm{~b}$. However, the velocity in case B was generally higher than in case A-except for points at $p>0.2$ and three other points in case 2, see Figure $5 \mathrm{~b}$. The basis on this fact and the measurements presented by Smyk et al. [23] can be assumed that the confinement plat reduces the velocity of SJ. The impact is minor, but this fact should be included in the design of SJA.

The negative impact of the confinement plat on the SJ velocity is due to the limit of the space around the orifice exit. The air sucked to the orifice in a different way Figure 6, and it can be demonstrated by the comparison of the minimal velocity in cases A and B. For this reason, in Figure 7 the percentage difference between the maximal Figure $7 \mathrm{a}$ and minimal Figure $7 \mathrm{~b}$ velocity in cases $\mathrm{B}$ and $\mathrm{A}$ is presented. The maximal velocity difference is ambiguous and is in the range from $-2.8 \%$ to $2.8 \%$. Based on the velocity measurements, it can be inferred that the confinement plat has no impact on the maximal velocity of generating SJ. In the case of minimal velocity, the difference between cases $\mathrm{A}$ and $\mathrm{B}$ is significant.

a)

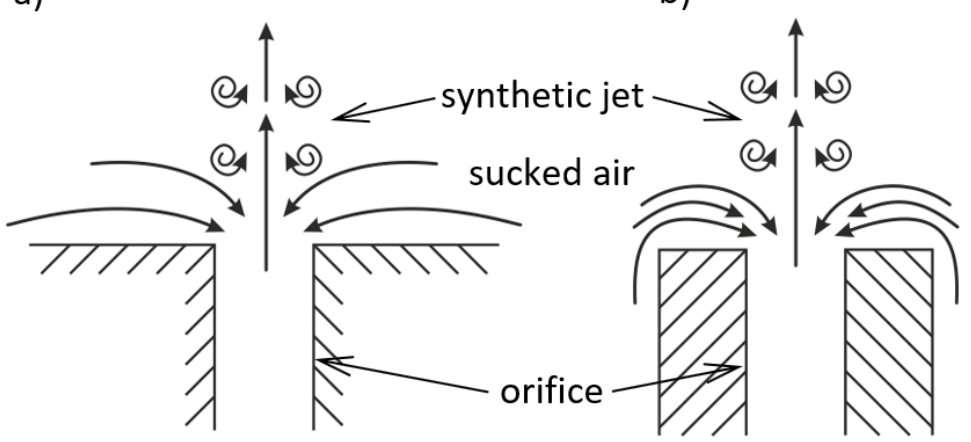

Figure 6. The supposed way of air ingestion for the synthetic jet with (a) and without (b) confinement plate.

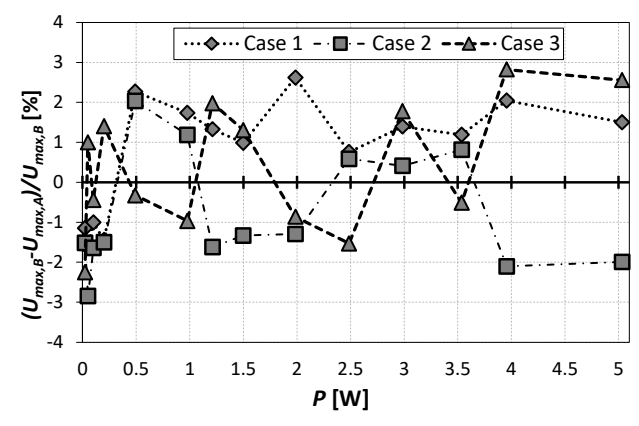

(a)

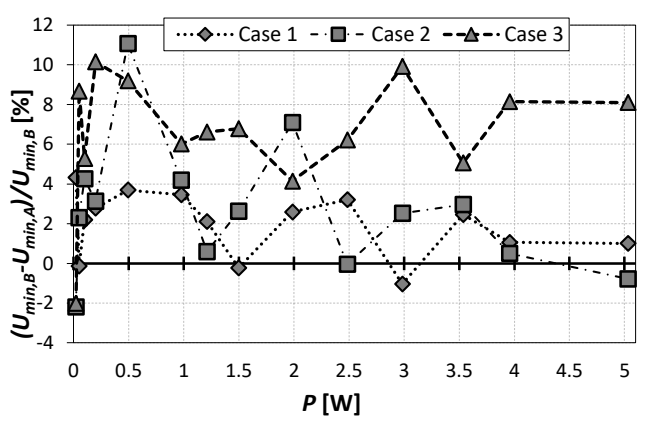

(b)

Figure 7. The percentage difference between the maximal (a) and minimal (b) centerline velocity in cases B and A as a function of real power, at the characteristic frequency and $x=0$.

Similarly, as in the case of the momentum velocity, the differences were the highest in case 3 and were in the range from $4.1 \%$ to $10.1 \%$-the both of velocities were negative, and the positive value in Figure $7 \mathrm{~b}$ means that the minimal velocity in case $B$ was smaller than in case A. In other words, the absolute value of the minimal velocity in case B was higher than in case A. So high differences cannot be caused by the uncertainty of measurements and show that the confinement plat has an impact on the SJA operation and SJ generation. The confinement plate decreased the velocity during the suction part of the period. Of 
course, the velocity value in the suction part of the operation period is not directly related to the momentum velocity but it affects it.

\subsection{Dimensionless Parameters}

The dimensionless stroke length as a function of a Reynolds number was presented in Figure 8. The parameters were dependent linear and in cases 2 and 3 was similar independent to confinement plate or the orifice height. The SJ formation criterion defined by Hollman et al. [36] has been met in all measurements range. The Reynolds number by measurements presented in this paper was in the range of $2300<R e<19,500$. The Stokes number was in the range of $46<S<62$.

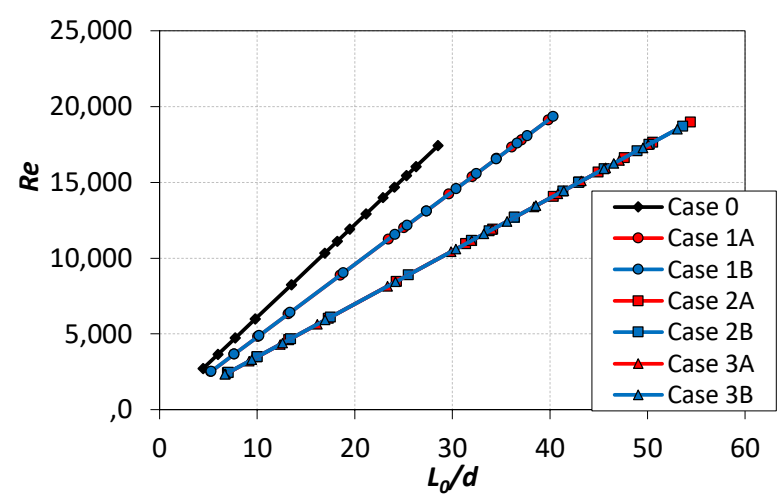

Figure 8. The dimensionless stroke length vs. the Reynolds number.

In this paper, the dimensionless parameters were calculated based on the centerline momentum velocity and in [23] based on the time-mean reaction force. Kordík et al. [29] showed that the ratio of the stroke length or Reynolds number calculated for the centerline velocity and calculated for the time- and spatially-averaged velocity depends on the stroke length and the geometry of SJA. Peszynski and Tesař [30] proved the same but for the continuous jet. Although the momentum centerline velocity and not the centerline velocity was used in this paper the above relationship should be maintained. The average-tocenterline ratio can be calculated as:

$$
\alpha=\frac{R e^{*}}{R e}=\frac{L_{0}^{*}}{L_{0}}
$$

where symbol * means the values from [23].

The average-to-centerline ratio calculated based on the Reynolds number is equal $\alpha_{R e}=0.63 \pm 0.05$, and based on the dimensionless stroke length $\alpha_{L}=0.34 \pm 0.02$. The values of the average-to-centerline ratio obtained by comparing the results presented in this paper and in [23] were presented in Figure 9. The difference between the two values is equal to two and is caused by the methodology of the Reynolds number calculation. The paper [23] used the methodology described by Gil [31] —errata were published for the both of papers [23,31]. Gil [31] used the velocity calculated on the basis of slug-velocity-profile $U$ to the calculation of the Reynolds number, and the time- and spatially-averaged velocity $U_{e}$ was used to the calculation of the dimensionless stroke length. The ratio between these two velocities is $U=2 U_{e}$. If the Reynolds number from the paper [23] will be calculated on the basis of the time- and spatially-averaged velocity $U_{e}$, then the average-to-centerline ratio calculated from Reynold number and dimensionless stroke length is $\alpha=0.35 \pm 0.02$. 


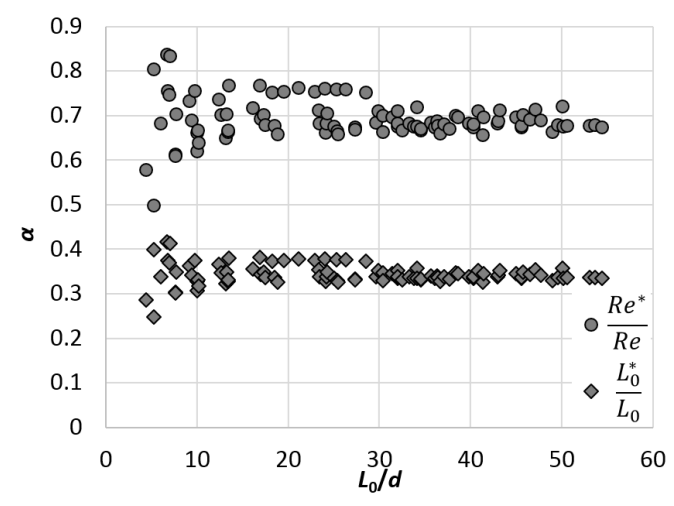

Figure 9. The average-to-centerline ratio vs. the dimensionless stroke length.

\subsection{Axial Velocities Profiles}

The axial velocity profile of centerline velocity was measured for the SJ in the range of $0<x / d<20$. The axial centerline momentum velocity was presented in Figure 10a and the comparison of the axial centerline momentum velocity in cases $A$ and $B$ to case 0 was presented in Figure 10b.

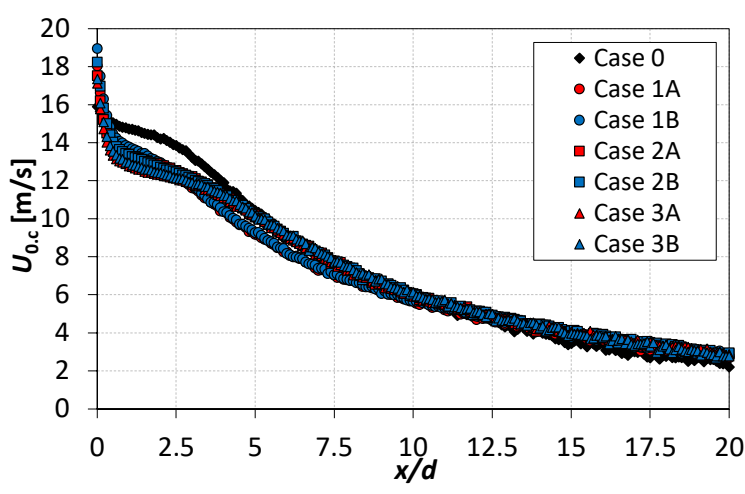

(a)

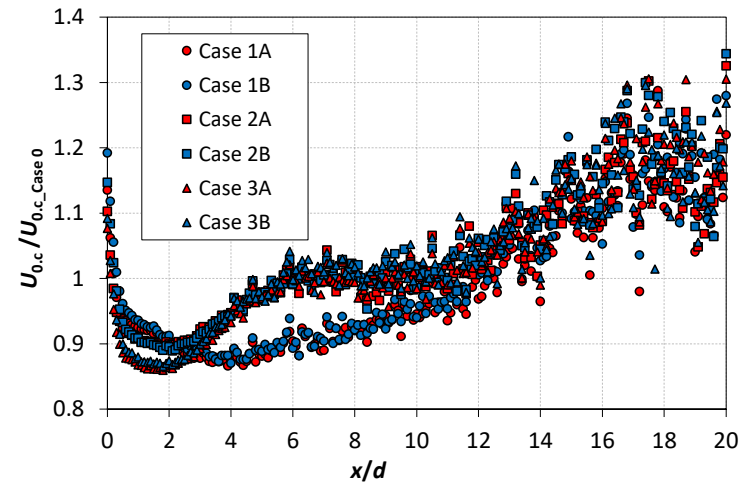

(b)

Figure 10. The axial centerline momentum velocity (a), and the axial centerline momentum velocity ratio (b) as a function of axial distance $x / d$, at the characteristic frequency and real power $p=5 \mathrm{~W}$.

The difference in the axial velocity between cases $\mathrm{A}$ and $\mathrm{B}$ was negligible and was about $2 \%$. The axial velocity in case B was higher than the velocity of case A. The axial centerline velocity showed the impact of the orifice length on the velocity. The velocity of case 0 was the smallest at $x=0$ Figure 10a at $x=0$, but the $S \mathrm{~J}$ in case 0 is higher than in other cases at some distance from the orifice. The axial centerline momentum velocity in case 0 was higher in the distance range of $0.3<x / d<6$ then in cases 2 and 3 , and in the distance range of $0.3<x / d<11.7$. The axial distance is the important parameter in the case of impinging SJ. Depending of the investigations the optimal axial distance between the orifice and cooled surface is recognized as $x / d=6.3-8.4$ [37], $x / d=5-8$ [38], $x / d=$ $5-7$ [39], $x / d=5-10$ [8] and the heat transfer is dependent of the SJ velocity. The heat transfer optimal distance overlaps a distance in which the velocity in case 0 was greater than the other.

The axial centerline momentum velocity in cases 2 and 3 were similar in all distance range. The velocity in case 1 was smaller than in cases 2 and 3 at the distance range of $2<x / d<11.7$. The distance $x / d=11.7$ was the point where any velocity value differences disappeared, and the scatter of the results was too large to be able to draw conclusions from it.

The maximal centerline velocity Figure 11a decreased with the axial distance for all cases except case 0 where the maximal velocity increased to the $x / d=2.1$ and then 
decreased. The maximal velocity in case 0 is higher than in cases 2 and 3 in the range of 0.8 $<x / d<7.1$ and is higher than in cases 1 in the range of $0.8<x / d<12.5$. The confinement plate had not a significant impact on the maximal centerline velocity profile.
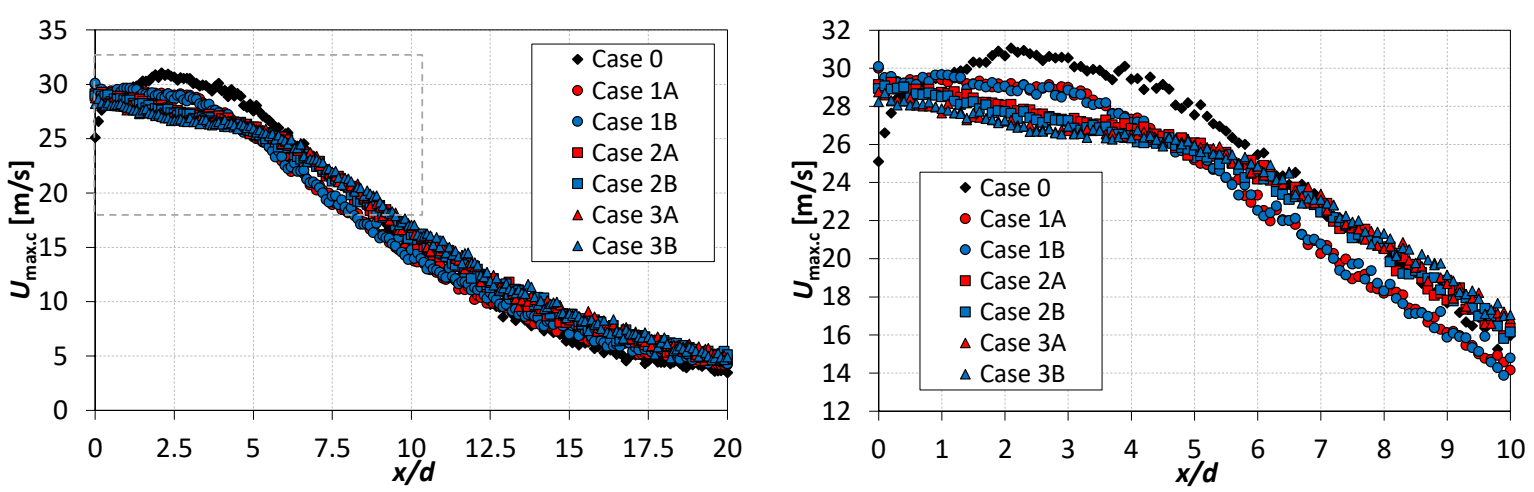

(a)
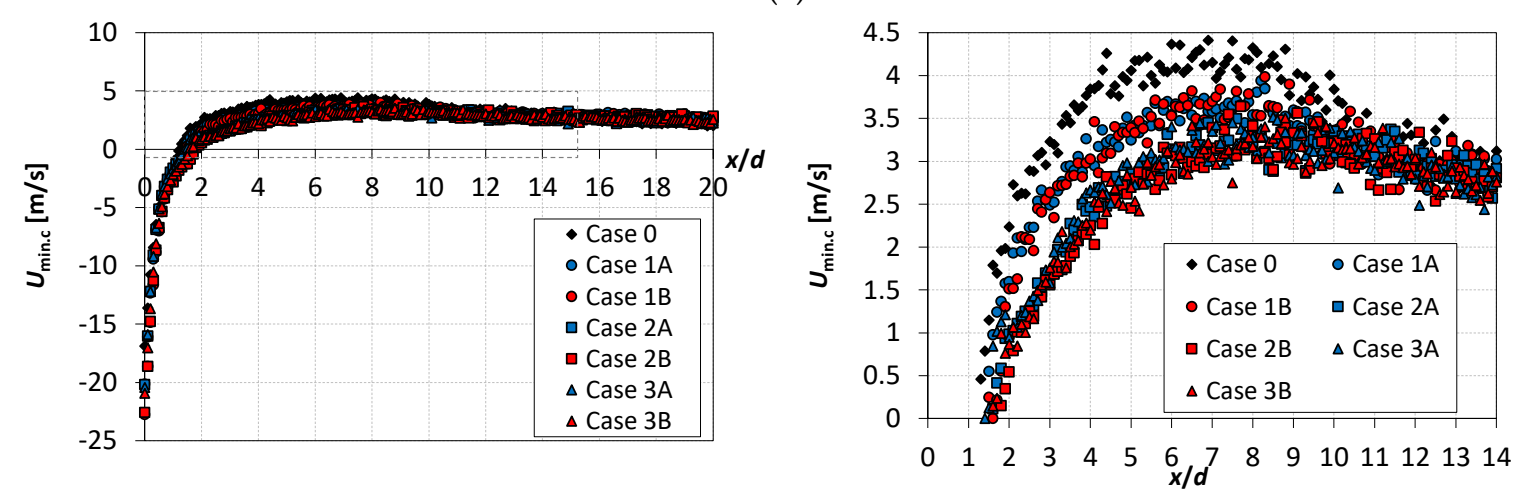

(b)

Figure 11. The maxima (a) and minimal (b) centerline velocity as a function of axial distance $x / d$ and close-ups on selected areas of the charts, at the characteristic frequency and real power $p=5 \mathrm{~W}$.

The minimal centerline velocity Figure $11 \mathrm{~b}$ in case 0 was higher than in cases 1 in the range of $1.4<x / d<12.5$, higher than in cases 2 and 3 in the range of $1<x / d<9$. The minimal velocity was higher in case $\mathrm{B}$ than in case $\mathrm{A}$ at the distance of $x / d<4$ in all cases but the difference between the minimal velocity in case B and in case A was bigger than 0.2 (doubled value of the measurement uncertainty, see Table 2) at the distance of $x / d<1.9$ for all measurements point. The difference was around $2.5 \mathrm{~m} / \mathrm{s}$ in case 1 and around $2.4 \mathrm{~m} / \mathrm{s}$ in case 2 . This confirms the assumption that the confinement plate impedes air ingestion by limits the area from which the air is sucked in the actuator. The supposed way of air ingestion was presented in Figure 6.

\section{Conclusions}

The velocity differences for the actuator with and without the confinement plate are small and for many of the measurement points were below the velocity measurements uncertainty. However, presented measurements proved that the confinement plate decreases the velocity of the SJ even above $5 \%$. The plate limits the area around the orifice and the velocity during the suction part of the operation is much smaller than in cases without a confinement plate. The area of the used plate was relatively big to the orifice area in case A, and the orifice wall thickness was $2 \mathrm{~mm}$ in case B. Based on the presented investigation it is impossible to determine, how the size of the front surface area of the orifice impacts the SJ but only whether it does.

On the basis of the presented investigation and previous research [23], the average-tocenterline ratio was calculated for the actuators as a $\alpha=0.35$. The range of the measurements was presented as the Reynolds number in a function of the dimensionless stroke 
length. The Reynolds number was in the range of $2300<R e<19,500$, and the Stokes number was in the range of $46<S<62$.

The impact of the confinement plate on the SJ velocity was also confirmed based on axial profiles of SJ. The coefficient plate impact was observed in the distance of $x / d<4$, but the orifice length had more of an impact than the plate. Summarizing all the facts the confinement plate has a negative impact on the parameter of SJ, especially the velocity. However, this impact is slight.

The presented results are significant because they showed the previous unresolved problem. However, due to the scale of the impact, the problem of the confinement plate will be secondary during the SJA design.

Author Contributions: Conceptualization, E.S., and R.S.; methodology, E.S.; software, E.S.; validation, R.S.; formal analysis, R.S.; investigation, R.S.; resources, E.S.; data curation, E.S.; writingoriginal draft preparation, E.S.; writing-review and editing, E.S. and R.S.; visualization, E.S.; supervision, R.S. All authors have read and agreed to the published version of the manuscript.

Funding: This work was supported by the National Center for Research and Development, Poland. Grant No.: LIDER/6/0024/L-10/18/NCBR/2019.

Institutional Review Board Statement: Not applicable.

Informed Consent Statement: Not applicable.

Data Availability Statement: Some or all data generated or used during the study are available from the corresponding author by request.

Conflicts of Interest: The authors declare no conflict of interest.

\section{Nomenclature}

$\begin{array}{ll}A & \text { confinement area, } \mathrm{m}^{2} \\ d & \text { orifice inner diameter, } \mathrm{m} \\ D & \text { cavity diameter, } \mathrm{m} \\ f & \text { excitation frequency, } \mathrm{Hz} \\ H & \text { cavity height, } \mathrm{m} \\ L_{0} & \text { stroke length, } \mathrm{m} \\ P & \text { real power, } \mathrm{W} \\ R e & \text { Reynolds number } \\ S & \text { Stokes number } \\ t & \text { orifice height, } \mathrm{m} \\ T & \text { oscillation period, } \mathrm{s} \\ x & \text { axial distance, } \mathrm{m} \\ u & \text { instantaneous velocity, } \mathrm{m} / \mathrm{s} \\ U & \text { characteristic velocity, } \mathrm{m} / \mathrm{s} \\ \text { Greek symbols } & \\ v & \text { kinematic viscosity, } \mathrm{m}^{2} / \mathrm{s} \\ \tau & \text { time, } \mathrm{s} \\ \text { Index } & \\ c & \text { centerline } \\ \text { min } & \text { minimal } \\ \text { max } & \text { maximal } \\ p-p & \text { peak-to-peak } \\ \text { Aberrations } & \\ \text { CTA } & \text { constant temperature anemometer } \\ \text { LIF } & \text { laser-induced fluorescence } \\ \text { PIV } & \text { particle image velocimetry } \\ \text { PMMA } & \text { poly(methyl methacrylate) } \\ \text { SJ } & \text { synthetic jet } \\ \text { SJA } & \text { synthetic jet actuator } \\ \text { ZNMF } & \text { zero-net mass-flux } \\ & \end{array}$




\section{References}

1. Wang, P.; Shen, C.B. Characteristics of mixing enhancement achieved using a pulsed plasma synthetic jet in a supersonic flow. J. Zhejiang Univ. Sci. A 2019, 20,701-713. [CrossRef]

2. Xia, Q.; Zhong, S. Enhancement of inline mixing with lateral synthetic jet pairs at low Reynolds numbers: The effect of fluid viscosity. Flow Meas. Instrum. 2017, 53, 308-316. [CrossRef]

3. Bagherzadeh, A.; Jalali, E.; Sarafraz, M.M.; Akbari, O.; Karimipour, A.; Goodarzi, M.; Bach, Q.-V. Effects of magnetic field on micro cross jet injection of dispersed nanoparticles in a microchannel. Int. J. Numer. Methods Heat Fluid Flow 2019, 30, 2683-2704. [CrossRef]

4. Lebon, B.; Nguyen, M.Q.; Peixinho, J.; Shadloo, M.S.; Hadjadj, A. A new mechanism for periodic bursting of the recirculation region in the flow through a sudden expansion in a circular pipe. Phys. Fluids 2018, 30, 031701. [CrossRef]

5. Arshad, A.; Jabbal, M.; Yan, Y. Synthetic jet actuators for heat transfer enhancement-A critical review. Int. J. Heat Mass Transf. 2020, 146, 118815. [CrossRef]

6. Ikhlaq, M.; Yasir, M.; Demiroplu, M.; Arik, M. Synthetic Jet Cooling Technology for Electronics Thermal Management-A Critical Review. IEEE Trans. Compon. Packag. Manuf. Technol. 2021, 11, 1156-1170. [CrossRef]

7. Trávnícek, Z.; Broucková, Z. Characterization of Impingement Heat/Mass Transfer to the Synthetic Jet Generated by a Biomimetic Actuator. J. Heat Transf. 2019, 141, 042203. [CrossRef]

8. Ghaffari, O.; Solovitz, S.A.; Arik, M. An investigation into flow and heat transfer for a slot impinging synthetic jet. Int. J. Heat Mass Transf. 2016, 100, 634-645. [CrossRef]

9. Li, S.; Luo, Z.; Deng, X.; Peng, W.; Liu, Z. Experimental investigation on active control of flow around a finite-length square cylinder using dual synthetic jet. J. Wind Eng. Ind. Aerodyn. 2021, 210, 104519. [CrossRef]

10. Jankee, G.K.; Ganapathisubramani, B. Scalings for rectangular synthetic jet trajectory in a turbulent boundary layer. J. Fluid Mech. 2021, 915, A57. [CrossRef]

11. Singh, P.K.; Sahu, S.K.; Upadhyay, P.K.; Jain, A.K. Experimental investigation on thermal characteristics of hot surface by synthetic jet impingement. Appl. Therm. Eng. 2020, 165, 114596. [CrossRef]

12. Singh, P.K.; Sahu, S.K.; Upadhyay, P.K. Experimental investigation of the thermal behavior a single-cavity and multiple-orifice synthetic jet impingement driven by electromagnetic actuator for electronics cooling. Exp. Heat Transf. 2020, 1-27. [CrossRef]

13. Jacob, A.; Shafi, K.; Roy, A.K.E.R. Heat Transfer Characteristics of Piston-Driven Synthetic Jet. Int. J. Thermofluids 2021, 11, 100104. [CrossRef]

14. Miró, A.; Soria, M.; Cajas, J.C.; Rodríguez, I.; Moulinec, C. Flow topology and heat transfer analysis of slotted and axisymmetric synthetic impinging jets. Int. J. Therm. Sci. 2021, 164. [CrossRef]

15. Zong, H.; Kotsonis, M. Effect of slotted exit orifice on performance of plasma synthetic jet actuator. Exp. Fluids 2017, 58, 17. [CrossRef]

16. Gupta, J.; Satish, S.S.; Saha, G.A.K. Vortex formation in a low aspect ratio synthetic jet. J. Flow Vis. Image Process. 2020, $27,117-141$. [CrossRef]

17. Bhapkar, U.S.; Srivastava, A.; Agrawal, A. Proper cavity shape can mitigate confinement effect in synthetic jet impingement cooling. Exp. Therm. Fluid Sci. 2015, 68, 392-401. [CrossRef]

18. Huang, L.; Yeom, T.; Simon, T.; Cui, T. An experimental and numerical study on heat transfer enhancement of a heat sink fin by synthetic jet impingement. Heat Mass Transf. 2021, 57, 583-593. [CrossRef]

19. Mangate, L.; Chaudhari, D.M.B. Experimental study on heat transfer characteristics of a heat sink with multiple-orifice synthetic jet. Int. J. Heat Mass Transf. 2016, 103, 1181-1190. [CrossRef]

20. Gil, P. Performance of special type heat sink with an integrated synthetic jet actuator. E3S Web Conf. 2019, 100, 00017. [CrossRef]

21. Gil, P. Experimental investigation on heat transfer enhancement of air-cooled heat sink using multiple synthetic jets. Int. J. Therm. Sci. 2021, 166, 106949. [CrossRef]

22. Feero, M.A.; Lavoie, P.; Sullivan, P.E. Influence of cavity shape on synthetic jet performance. Sens. Actuators A Phys. 2015, 223, 1-10. [CrossRef]

23. Smyk, E.; Przeszłowski, Ł.; Strzelczyk, P.M. Impact of the confinement plate on the synthetic jet. AIP Adv. 2020, 10, 105204, Erratum in 2021, 11, 039901. [CrossRef]

24. Chiatto, M.; Palumbo, A.; de Luca, L. Design approach to predict synthetic jet formation and resonance amplifications. Exp. Therm. Fluid Sci. 2019, 107, 79-87. [CrossRef]

25. De Luca, L.; Girfoglio, M.; Chiatto, M.; Coppola, G. Scaling properties of resonant cavities driven by piezo-electric actuators. Sens. Actuators A Phys. 2016, 247, 465-474. [CrossRef]

26. Gil, P.; Wilk, J.; Korzeniowski, M. Helmholtz Resonance Frequency of the Synthetic Jet Actuator. Appl. Sci. 2021, 11, 5666. [CrossRef]

27. Kordík, J.; Trávníček, Z. Optimal diameter of nozzles of synthetic jet actuators based on electrodynamic transducers. Exp. Therm. Fluid Sci. 2017, 86, 281-294. [CrossRef]

28. Gil, P.; Wilk, J.; Smusz, R.; Gałek, R. Centerline heat transfer coefficient distributions of synthetic jets impingement cooling. Int. J. Heat Mass Transf. 2020, 160, 120147. [CrossRef]

29. Kordík, J.; Trávníček, Z.; Timchenko, V.; Ismail, N.A. The predominant effect of stroke length on velocity profiles at the exit of axisymmetric synthetic jet actuators. Int. J. Heat Fluid Flow. 2017, 66, 197-208. [CrossRef] 
30. Peszynski, K.; Tesař, V. Algebraic model of turbulent flow in ducts of rectangular cross-section with rounded corners. Flow Meas. Instrum. 2020, 75. [CrossRef]

31. Gil, P. Synthetic jet Reynolds number based on reaction force measurement. J. Fluids Struct. 2018, 81, 466-478, Corrigendum in 2021, 101, 103211. [CrossRef]

32. Kordík, J.; Trávníček, Z. Integral Quantities of Axisymmetric Synthetic Jets Evaluated from a Direct Jet Thrust Measurement. Flow Turbul. Combust. 2019, 103, 827-844. [CrossRef]

33. Gil, P.; Strzelczyk, P. Performance and efficiency of loudspeaker driven synthetic jet actuator. Exp. Therm. Fluid Sci. 2016, 76, 163-174. [CrossRef]

34. Smyk, E.; Wawrzyniak, S.; Peszyński, K. Synthetic jet actuator with two opposite diaphragms. Mech. Mech. Eng. 2020, $24,17-25$. [CrossRef]

35. Gil, P.; Smyk, E. Synthetic jet actuator efficiency based on the reaction force measurement. Sens. Actuators A Phys. 2019, 295, 405-413. [CrossRef]

36. Holman, R.; Utturkar, Y.; Mittal, R.; Smith, B.L.; Cattafesta, L. Formation criterion for synthetic jets. AIAA J. 2005, 43, 2110-2116. [CrossRef]

37. Kercher, D.; Lee, S.J.B.; Brand, O.; Allen, M.G.; Glezer, A. Microjet cooling devices for thermal management of electronics. IEEE Trans. Compon. Packag. Technol. 2003, 26, 359-366. [CrossRef]

38. Mangate, L.; Yadav, H.; Agrawal, A.; Chaudhari, M. Experimental investigation on thermal and flow characteristics of synthetic jet with multiple-orifice of different shapes. Int. J. Therm. Sci. 2019, 140, 344-357. [CrossRef]

39. Gil, P.; Wilk, J. Heat transfer coefficients during the impingement cooling with the use of synthetic jet. Int. J. Therm. Sci. 2020, 147, 106132. [CrossRef] 